Kansas State University Libraries

New Prairie Press

\title{
DAILY SOLAR RADIATION ESTIMATED FROM TKMPERA TURE RECORDS
}

D. W. Meek

Follow this and additional works at: https://newprairiepress.org/agstatconference

Part of the Agriculture Commons, and the Applied Statistics Commons

\section{(c) $(1) \ominus$}

This work is licensed under a Creative Commons Attribution-Noncommercial-No Derivative Works 4.0 License.

\section{Recommended Citation}

Meek, D. W. (1998). "DAILY SOLAR RADIATION ESTIMATED FROM TKMPERA TURE RECORDS,"

Conference on Applied Statistics in Agriculture. https://doi.org/10.4148/2475-7772.1282

This is brought to you for free and open access by the Conferences at New Prairie Press. It has been accepted for inclusion in Conference on Applied Statistics in Agriculture by an authorized administrator of New Prairie Press. For more information, please contact cads@k-state.edu. 


\title{
DAILY SOLAR RADIATION ESTIMATED FROM TEMPERATURE RECORDS
}

\author{
D.W. Meek, USDA-ARS-MWA National Soil Tilth Lab., Ames, IA 50011-4420 USA
}

\begin{abstract}
Crop growth models and other environmental analyses require the input of daily global solar radiation values. Unfortunately many locations lack long-term solar radiation data. Most agricultural experiment stations, however, have daily temperature records. Also they are often the locations for which crop growth simulations are conducted. In an unpublished manuscript in the field of agricultural meteorology, researchers wanted to address this need. Specifically they wanted to estimate historical daily global solar radiation using daily air temperature data records by adapting a single published empirical intrinsically nonlinear model, a form of the Weibull curve. In order to help future research in the given field, this paper argues that the selected model is a poor choice. Two independent long-term data sets that come from a similar climate to that of the researchers' are used, one for model development and the other for testing model prediction. Through the use of performance statistics on the cross-validation, three alternative models are offered for comparison (the performance statistics are accepted by researchers in the agricultural meteorology discipline). The results give no reason to favor the researchers' selected model. Furthermore no model performed well under advective conditions. Future research should consider finding a better means to account for advection, developing and evaluating other models, and justifying the assumptions of the methodology to be employed.
\end{abstract} Keywords: Bristow-Campbell Model, Fox Statistics, cross-validation

\section{Introduction}

Recently I was asked to review a manuscript for an agricultural meteorology journal. The researchers specifically wanted to estimate historical solar radiation using daily air temperature data records with a model. The need for the estimates is reviewed in the next section. The researchers presented just one model, a modification (requiring 12 parameters) of the BristowCampbell Model (1984), an intrinsically nonlinear model. The researchers' model was developed from a 30 year record of daily data that came from an NWS station located in a Midwestern town with rural surroundings. As is commonly the practice in this research field, information on the solution existence and uniqueness, error surface topology, convergence, parameterization, error structure, etc. was not reported (rarely is more than the coefficient of determination reported). The model was tested via cross-validation on several independent sets located at various research sites in the same state. All had a 10 year period of record. Some of the performance statistics for the cross-validation proposed by Fox et al. (1981), that are commonly used by researchers in this field, were reported. These statistics are defined in the methods section. No performance goal in terms of any of the Fox statistics was set. Problems were apparent and so the work was not acceptable.

The purpose of this work then is to show that the given Bristow-Campbell Model, especially as cast, is a poor choice. I present the analysis in a way that agrometeorological researchers readily accept, cross-validation analysis. The Fox statistics along with graphs are used to assess the results. Two comparable long-term data sets from a nearby state with a similar climate are used. One is the development set and the other is the prediction set. Three simpler alternative 
models are developed and evaluated along with the Bristow-Campbell model. A comparison of performance results is then presented along with some recommendations for additional research.

\section{Background on the research problem}

Daily solar radiation is an important measurement needed for various analyses in many of the applied sciences from engineering to environmental science (see e.g., Iqbal, 1983). In agronomy a major use is for crop growth modeling (e.g., Meek et al., 1984). Crop growth models require the input of daily global solar radiation to estimate intercepted photosynthetically active radiation which in turn is used to estimate photosynthesis and crop growth. Many locations of interest lack long-term solar radiation data. Most agricultural experiment stations, however, have historical daily data conforming to a set standard (USDC-NWS, 1972) that include daily maximum and minimum air temperature records along with precipitation. Agricultural experiment stations are often the locations which are the best sites for developing and evaluating crop growth simulations because they are the places where detailed histories and measurements of crop growth and development are available. Nowadays automated stations that include solar radiation are becoming the standard for experiment stations in the United States but generally the period of record is less than a decade (e.g., Meyers and Hubbard, 1992). In the lesser developed countries automated weather stations at agricultural sites are rare. Thus, for many purposes including historical crop growth modeling, the need for solar radiation estimates at places where it is not measured still exists (see e.g., Bland and Clayton, 1994; or Hargreaves et al., 1985).

The job of reconstructing the solar radiation record from other meteorological data is not new. Time series on annual data is of great concern to climate change research (e.g., Lean et al., 1995). Some of the work in agronomy follows. Richardson (1985), Hargreaves et al. (1985), and Bristow and Campbell (1984) have proposed daily-based nonlinear models with the daily temperature range as the predictor. Not one used the World Meteorological Organization (WMO) recommended 30 year period of record (WMO, 1967). Hook and McClendon (1992) used a multiple linear regression model for a 13 year period of record.

\section{Data}

The WMO has recommended a 30 year period of record for establishing climatological normals (WMO, 1967). Recent work with solar radiation has followed the WMO standard (e.g., Meek, 1997; NREL, 1992 \& 1995). An independent development set and a prediction set each with a 30 year period of daily records were selected for this analysis because single crossvalidation is an accepted practice in the field of agricultural meteorology. Some general considerations for working with the given type of data along with summaries of the prediction and development sets follow.

\subsection{Variable Definitions and Modeling Considerations}

All models considered are based on a broadband transmittance definition or a modification of it (formally the basic concept of transmittance is spectral). Broadband transmittance, the dependent variable which is denoted $\tau$, is simply estimated by a ratio, $\tau=\mathbf{R}_{\mathbf{S}} / \mathbf{R}_{\text {Sext }}$. Here $\mathbf{R}_{\mathrm{S}}$ is the measured daily global solar shortwave radiation (generally the $0.3-3.0 \mu \mathrm{m}$ wave-band) at the ground station and $\mathbf{R}_{\text {Sext }}$ is the calculated extraterrestrial daily total value. Based purely on solar 
geometry and the solar constant, routines for estimating $\mathbf{R}_{\text {Sext }}$ for subdaily intervals, often hours, can be found in standard texts like Iqbal(1983). Daily values are then the sum of the hourly values. The daily units used here are megajoules per square meter $\left(\mathrm{MJ} \mathrm{m}^{-2}\right)$. Throughout the year $\mathbf{R}_{\text {Sext }}$ varies approximately sinusoidally with the day of the year peaking at the summer solstice in the Northern Hemisphere (about day 172). The $\mathbf{R}_{\mathbf{S}}$ measurement is the sum of direct beam and diffuse solar radiation. On a completely overcast day the direct beam can be negligible. Otherwise it is the dominant term. The attenuation of solar radiation as it passes through the atmosphere is known as radiative transfer and is the superposition of numerous spectral processes (see e.g., Iqbal, 1983). At a given location there is a climatic based upper limit for $\mathbf{R}_{\mathrm{S}}$ often called a "clear day curve" and denoted as $\mathbf{R}_{\mathrm{Sc}}$ (Meek, 1997). Thus there is also a bounding curve for $\tau$, i.e., $\tau_{\mathrm{c}}=\mathbf{R}_{\mathrm{Sc}} \mathbf{R}_{\mathrm{Sext}}$. The two broken curves in Fig. 1 show $\mathbf{R}_{\mathrm{Sext}}$ and $\mathbf{R}_{\mathrm{Sc}}$ curves developed for Ames, IA.

Modeling $\mathbf{R}_{\mathbf{S}}$ physically without considerable knowledge of many atmospheric variables that are generally not available at agricultural experiment stations has not been feasible until recently. Some possibilities are suggested in the discussion section. Instead, in general, empirical models of $\tau$ have been used like those given in the background section. If a model of $\tau$ for a given location is known then daily solar radiation can be easily estimated, i.e., $\mathbf{R}_{\mathbf{S}}=\tau \mathbf{R}_{\text {Sext }}$.

In previous research for modeling $\tau$ with the temperature range $(\Delta T$, the independent variable), $\Delta \mathrm{T}$ has been used as is and with modifications. Generally the daily temperature range is given by $\Delta T(J)=T_{\text {max }}(J)-T_{\min }(J)$ where $\mathrm{J}$ is the daily time step sequence index and $T_{\max }$ and $\mathrm{T}_{\min }$ are the daily maximum and minimum surface air temperature extremes measured with liquid in glass recording thermometers. The assumption behind the proposed relationship is that the temperature range is driven by the amount of radiation received. This is plausible only in the absence of the movement of a large, comparatively warmer or cooler air mass into the observation area, i.e., advection. Bristow and Campbell(1984) arbitrarily adjusted each temperature range datum for advection by defining it as $\Delta \mathrm{T}_{\mathrm{a}}(\mathrm{J})=\mathrm{T}_{\text {max }}(\mathrm{J})-0.5\left(\mathrm{~T}_{\text {min }}(\mathrm{J})+\mathrm{T}_{\text {min }}(\mathrm{J}+1)\right)$. Next selected datum were further arbitrarily scaled to $75 \%$ of their value under two given precipitation conditions (the resulting temperature range variable is designated $\Delta \mathrm{T}_{\mathrm{b}}$ ). So $\Delta \mathrm{T}$ can be designated as unadjusted, $\Delta \mathrm{T}_{\mathrm{a}}$ as adjusted, and $\Delta \mathrm{T}_{\mathrm{b}}$ as fully adjusted.

The counter example models proposed in this work make use of another variable known as relative optical air mass (shortened to air mass) and is denoted $\mathrm{m}_{\mathrm{a}}$. A conceptual definition follows. Assume the atmosphere is a spherical shell around the planet's surface. At solar noon at an equinox on the equator $\mathrm{m}_{\mathrm{a}}=1$, its lowest value, meaning there is one atmospheric path length that incoming direct beam solar radiation passes through. At sunrise or sunset it is at its maximum daily value having to go through several atmospheric path-lengths. Hence under normal conditions at any other place or time $m_{a}>1$. Like the site specific $\mathbf{R}_{\text {Sext }}$ curve, $m_{a}$ can be uniquely computed for a given set of coordinates, sunshine period, and hour angle with standard routines (see e.g., Iqbal, 1983). Daily averages weighted by $\mathbf{R}_{\text {Sext }}$ can then be estimated. For Central Iowa daily $\mathrm{m}_{\mathrm{a}}$ approximately varies sinusoidally being about a half year out of phase with $\mathbf{R}_{\text {Sext }}$ and ranges from about 1.6 at the summer solstice to about 3.5 at the winter solstice (see the solid line curve in Fig. 1). 


\subsection{Prediction Set}

Daily $\mathbf{R}_{\mathrm{S}}$ (converted to units of $\mathrm{MJ} \mathrm{m}^{-2}$ ), $\mathrm{T}_{\max }$, and $\mathrm{T}_{\min }$ (converted to ${ }^{\circ} \mathrm{C}$ ), and precipitation (denoted $P$ and converted to $\mathrm{mm}$ ) data for Ames, IA were obtained from the Iowa State University (ISU) Experiment Station. The data were recorded from 1960 through 1989. Details on the instrumentation and procedures are available (see Meek, 1997 and Baker and Klink, 1975). The geographic coordinates for Ames are $42.03^{\circ} \mathrm{N}, 93.80^{\circ} \mathrm{W}$, and $335 \mathrm{~m}$ elevation. The data were not formally quality controlled and have known problems and outliers. Of serious consequence, up until the early 1980s data were recorded on strip charts and daily values were obtained via planimetry. The methodology could have introduced a $5 \%$ or more error, possibly tending toward systematic over-estimation of the daily values $\left(\approx 1.25 \mathrm{MJ} \mathrm{m}^{-2}\right)$. Consequently predictions may be somewhat underestimated. Later $\mathbf{R}_{\mathrm{S}}$ data were numerically integrated. A few $\mathbf{R}_{\mathrm{S}}$ values exceeded the extraterrestrial value and so were excluded from the analyses. Finally some temperature records were excluded because they had $\mathrm{T}_{\min }>\mathrm{T}_{\max }$. Site specific $\mathbf{R}_{\mathrm{Sext}}$ and $\mathbf{R}_{\mathrm{Sc}}$ curves were developed for both the prediction and development sets.

\subsection{Development Set}

Daily data for Des Moines, IA were calculated from a serially complete quality controlled 30year record (1961-1990) that includes total and component shortwave irradiance data as well as many other meteorological variables including precipitation and the temperature record, all on an hourly basis. Daily values in metric units were calculated from the hourly data. This data record comes from the Solar and Meteorological Observation Network database (SAMSON for short and a.k.a. NSRDB for National Solar Radiation Data Base) which has 239 sites throughout the United States and its commonwealths (NREL, 1992; NREL, 1995). The Des Moines Station (WBAN 14933) geographic coordinates are $41.52^{\circ} \mathrm{N}, 93.65^{\circ} \mathrm{W}$, and $294 \mathrm{~m}$ elevation. The quality control procedure is formally documented (NREL, 1993). The daily $\Delta \mathrm{T}$ data for a SAMSON set are thus from hourly averages and not from point extremes. The $\Delta \mathrm{T}$ data are probably foreshortened by a factor of 0.916 compared to that based on point extremes. The given factor is based on an analysis of 5 years of data records from an automated station for a site about $5 \mathrm{~km}$ south of Ames, IA in the Walnut Creek Watershed with approximate coordinates of $93^{\circ} 38^{\prime}$ $\mathrm{N}, 41^{\circ} 58^{\prime} \mathrm{W}, 305 \mathrm{~m}$ elevation (Sauer and Hatfield, 1994). Hence the $\Delta \mathrm{T}$ data were accordingly adjusted.

\section{Models and methodology}

First a summary of the accepted practices for model evaluation in the meteorology literature is given. Then the original Bristow-Campbell model is reviewed followed by the modified version presented in the manuscript under consideration. Finally three simpler alternatives are presented.

\subsection{Accepted General Practices}

Rarely do articles in this research field explicitly state regression assumptions yet alone report in reasonable detail the model development results. In most cases ordinary least squares regression (OLS) is used and models are developed with an additive error structure and the assumptions that are associated with OLS are implicit. Although concerns about the OLS method and assumptions are raised in the discussion, in this analysis they are employed to be 
consistent with the extant practice. The models are developed with the Des Moines data set. The prediction data set (for Ames, IA) is used to compare the models' performance.

Some or all of the model comparison statistics suggested by Fox (1981) are often reported by agricultural meteorologists. This methodology was originally intended for assessing large deterministic or simulation systems but has come to be employed for regression models too. The observations, $\mathrm{O}$, are treated as the dependent variable and the model predictions, $\mathrm{P}$, are treated as the independent variable. The statistics are the means of $\mathrm{O}$, denoted $\overline{\mathrm{O}}$, and $\mathrm{P}$, denoted $\overline{\mathrm{P}}$; the mean bias error (the difference of $\overline{\mathrm{O}}$ and $\overline{\mathrm{P}}$, a.k.a., Bias) and its variance; the root mean square error (RMSE); the mean absolute error (MAE); and the Pearson correlation coefficient, $r(\mathrm{O}, \mathrm{P})$. Also the $\mathrm{O}$ and $\mathrm{P}$ medians, the ratio of the means $(\overline{\mathrm{O}} / \overline{\mathrm{P}})$, and the Spearman correlation coefficient are added to the tabled results. If the data are reasonably comparable then, of course, $\mathrm{O}=\mathrm{P}$ so $\overline{\mathrm{O}} / \overline{\mathrm{P}} \approx 1$ or $\overline{\mathrm{O}} \approx \overline{\mathrm{P}}$, the $\mathrm{O}$ and $\mathrm{P}$ distributions are similar with a zero mean bias error (Bias $\approx 0$ ), and other diagnostics reveal no problems. The Berg-plot (1992) is useful to graphically present and assess most of these comparisons. A Berg-plot shows univariate statistics in the form of a box-whisker plot on both the dependent and independent variables as well as on their difference, the bias. In these box-plots the lower end of the box is the 25 th percentile (first quartile), the line in the middle of the box is the 50th percentile (median), the top of the box is the 75th percentile (third quartile), so the box represents the middle $50 \%$ of the data (the interquartile range). The plus sign is the arithmetic mean, the end of the bottom whisker is the 5th percentile, the end of the top whisker is the 95th percentile, and the asterisks are the minimum and maximum values.

\subsection{The original Bristow-Campbell model}

The original Bristow and Campbell model (1984), a form of the Weibull curve, is given by

$$
\tau=\mathrm{A}\left(1-\exp \left(-\mathrm{B} \Delta \mathrm{T}_{\mathrm{b}}^{\mathrm{C}}\right)\right)
$$

In eq. (1) $A, B$, and $C$ are empirical constants with $A$ bounding the estimate to a maximum value that can be achieved on very clear days, i.e., A should be $\tau_{c}$. The model is really an empiricism. The authors did not make any claim to the contrary.

\subsection{The modified Bristow-Campbell model}

The proposed modification of the Bristow and Campbell model initially was

$$
\tau=\mathrm{A}(\mathrm{I})\left(1-\exp \left(-\mathrm{B}(\mathrm{I}) \Delta \mathrm{T}_{\mathrm{a}}^{\mathrm{C}(\mathrm{I})}\right)\right)
$$

In eq. (2a) $A, B$, and $C$ are analogous to the eq. (1) constants but they change with season ( $I=1$, $2,3,4$ corresponding to spring, summer, fall, and winter). So there are 12 parameters! In a revision, rather than try another model, eq. (2a) became

$$
\tau=\mathrm{A}(\mathrm{I})\left(1-\exp \left(-\mathrm{B}(\mathrm{I}) \Delta \mathrm{T}_{\mathrm{a}}^{\mathrm{C}(\mathrm{I})} / \mathbf{R}_{\text {Sext }}\right)\right)
$$

The earlier work resulted in a negative bias for the $A$ ( I )'s so they were next estimated graphically but still were probably too low. The $\mathbf{R}_{\text {Sext }}$ divisor was introduced to help reduce seasonal biases. In both cases a nonlinear least first power procedure (the L1 norm) from a popular commercial package was employed but no information either about the routine or the regression results was reported. In order to try to parallel the researchers' methodology the A(I) 
values for my analysis were fixed to the 95 th percentile of the seasonal $\tau_{c}$ frequency distribution in place of using arbitrary graphical estimates. Also, by using Ramsay's robust $\mathrm{E}_{\mathrm{a}}$ for the weight, generalized least squares are employed instead of an L1 routine.

If, indeed, some form of eq. (1) is appropriate and needs seasonal adjustments, a simpler alternative with fewer parameters is possible. For example, one alternative is

$$
\tau_{\mathrm{a}}=\left(1-\exp \left(-\left(\mathrm{B}_{0} \mathrm{~m}_{\mathrm{a}}+\left(\mathrm{B}_{1} / \mathrm{m}_{\mathrm{a}}\right) \Delta \mathrm{T}_{\mathrm{b}}^{\mathrm{C}(\mathrm{ma})}\right)\right)\right.
$$

In eq. (2c) $\tau_{\mathrm{a}}=\mathbf{R}_{\mathrm{S}} / \mathbf{R}_{\mathrm{Sc}}$ and $\mathrm{C}\left(\mathrm{m}_{\mathrm{a}}\right)=\mathrm{C}_{0}+\mathrm{C}_{1} \mathrm{~m}_{\mathrm{a}}$. This form eliminates $\mathrm{A}$ and continuously adjusts $\mathrm{B}$ and $\mathrm{C}$.

\subsection{Alternative Models}

The motivation for the selected models is provided in the discussion section. First, however, here are some more definitions. Both $\tau$ and $\Delta \mathrm{T}$ can also be seasonally adjusted by dividing by $\mathrm{m}_{\mathrm{a}}$. So now $\tau$ becomes $\tau_{\mathrm{m}}=\mathbf{R}_{\mathrm{S}} /\left(\mathbf{R}_{\text {Sext }} \mathrm{m}_{\mathrm{a}}\right)$ and $\Delta \mathrm{T}$ becomes $\Delta \mathrm{T}_{\mathrm{m}}=\Delta \mathrm{T} / \mathrm{m}_{\mathrm{a}}$. The simplest model to consider is just the line

$$
\tau_{\mathrm{m}}=\mathrm{A}_{0}+\mathrm{A}_{1} \Delta \mathrm{T}_{\mathrm{m}}
$$

Through indicator variables in a linear regression or nonlinear regression a two population version of eq. (3) can be defined. Using a nonlinear regression procedure, let $\tau_{\mathrm{m}}$ be

$$
\tau_{m}=\left\{\begin{array}{l}
A_{00}+A_{01} \Delta T_{m}, \Delta T_{m} \leq \Delta T_{m c} \\
A_{10}+A_{11} \Delta T_{m}, \Delta T_{m}>\Delta T_{m}
\end{array}\right\}
$$

where $\Delta \mathrm{T}_{\mathrm{mc}}=\left(\tau_{\mathrm{mc}}-\mathrm{A}_{00}\right) / \mathrm{A}_{01}$ where $\tau_{\mathrm{mc}}=\tau_{\mathrm{c}} / \mathrm{m}_{\mathrm{a}}$. In this model if the estimate for the first group exceeds $\tau_{\mathrm{mc}}$ (equivalent to $\mathbf{R}_{\mathrm{S}}>\mathbf{R}_{\mathrm{Sc}}$ ) then the second line is used instead.

\section{Results and discussion}

The Fox Statistics (1981) for the tested models are listed in Table 1. Berg-plots accompanied with annual cycle model observation/prediction difference plots are shown in Figs. 2 and 3 (model $2 \mathrm{~b}$ in Fig. 2A\&B, model 2c in Fig. 2C\&D, model 3 in Fig. 3A\&B, and model 4 in Fig. 3 $C \& D)$. While all positive functions tend to predict in the right direction, they do not do the job equally well! Clearly two to four parameters can do as good a job or better than the 12 in eq. (2b)! Formal tests like Fisher's Z-test on correlations can be done to help confirm what an inspection of the results suggests. In practice, though, researchers mainly make a selection by ranking the desired statistics. Sometimes an O-P regression line is reported. By any means of assessment, these results don't favor either Bristow-Campbell form, especially eq. (2b), over the alternatives. More interestingly, upon further analysis, none of the listed models is entirely satisfactory - all exhibiting heteroscedasticity with larger scatter in the late spring through early summer. In fact all the differences form a nice inverse funnel when plotted against $\mathrm{m}_{\mathrm{a}}$. Also all are biased low although perhaps not seriously for eqs. (3) and (4) when the possible upward bias in the Ames $\mathbf{R}_{\mathrm{S}}$ data is considered. Moreover, there is considerable and justifiable room for improvement in the predictions. Also consideration of the results and diagnostics on the development set, which are not generally reported, would have provided much insight into some of the problems. 


\subsection{Variable definition, selection, and other data considerations}

Regardless of the preceding results, a researcher needs to question and justify the need for using an intrinsically nonlinear model. Data analyses suggest that all of the dependent or independent variables are non-normal and autocorrelated. Furthermore there is possible heteroscedasticity. Bristow and Campbell (1983) showed a scatterplot for their data which came from a non-Midwestern climate and only had a one year period of record. Visually it did display slight curvature but not a sigmoid. It was more like a diminishing returns curve. One could question if an asymptote was apparent. Except for a very few points, the scatter appearance was also consistent with heteroscedasticity, possibly displaying a widening funnel in a positive linear relationship. In addition there appears to be an upper boundary for $\tau$ across all $\Delta \mathrm{T}_{\mathrm{b}}$ values consistent with a $\tau_{c}$ upper boundary. From the physical assumptions for a transmittancetemperature range relationship one could argue for a linear relationship if advection adjustments are done. More importantly, is this scatter reproducible?

In the work under consideration a scatter plot of the researchers' 30 year data was similar to that for the Ames. This finding is interesting because $\Delta \mathrm{T}_{\mathrm{a}}$ not $\Delta \mathrm{T}_{\mathrm{b}}$ was used. An argument for using $\Delta \mathrm{T}_{\mathrm{a}}$ was given based on regional climatic conditions. Moreover $\Delta \mathrm{T}_{\mathrm{a}}$ was defined as

$$
\Delta \mathrm{T}_{\mathrm{a}}=\mathrm{T}_{\max }(\mathrm{J})-\left(\mathrm{T}_{\min }(\mathrm{J})+\mathrm{T}_{\min }(\mathrm{J}-1)\right) / 2
$$

rather than as

$$
\Delta \mathrm{T}_{\mathrm{a}}=\mathrm{T}_{\max }(\mathrm{J})-\left(\mathrm{T}_{\min }(\mathrm{J})+\mathrm{T}_{\min }(\mathrm{J}+1)\right) / 2 .
$$

Based on unreported analyses, the latter $\Delta \mathrm{T}_{\mathrm{a}}$ estimator was used in this research because it worked better. In either case the scatter in the plot was vastly greater than that in Bristow and Campbell. This scatter plot needs to be carefully considered.

In any $\tau$ model there is another possible independent variable to consider. It is the daily average air temperature,

$$
\overline{\mathrm{T}}=\left(\mathrm{T}_{\max }+\mathrm{T}_{\min }\right) / 2 \text {. }
$$

Average air temperature can be used to indicate advection. Specifically, when $\Delta \mathrm{T}(\mathrm{J})=\mathrm{T}(\mathrm{J})-\mathrm{T}(\mathrm{J}-1)$ and/or $\Delta \mathrm{T}(\mathrm{J}-1)$ are large then advection is almost certainly occurring. Figure 4 is a montage showing the relationship $\tau$ versus $\Delta \mathrm{T}, \Delta \mathrm{T}_{\mathrm{a}}$, and $\Delta \mathrm{T}_{\mathrm{b}}$ for all the Ames data as well as for 30 year median based daily norms developed from the entire data set. Figure 5 shows the same for $\tau_{\mathrm{m}}$ versus $\Delta \mathrm{T}_{\mathrm{m}}$. Some very interesting patterns are revealed. Now notice most of the outliers in Figs. $4 \mathrm{~A}-\mathrm{C}$ and 5A, especially ones to the right side, are associated with large absolute value $\Delta \bar{T}(\mathrm{~J})$ or $\Delta \overline{\mathrm{T}}(\mathrm{J}-1)$ observations, i.e., advection. Also notice $\Delta \mathrm{T}$ shows the highest linear relationship with $\tau$ (Fig. 4A) while $\Delta \mathrm{T}_{\mathrm{a}}$ shows the lowest (Fig. 4B). All the patterns shown in Figs. 4 and 5 were also evident in the Des Moines data set. Thus $\Delta \mathrm{T}_{\mathrm{a}}$ and $\Delta \mathrm{T}_{\mathrm{b}}$ are not really adjusting for advection very well.

\subsection{Modeling considerations}

Equation (4), which works the best, was chosen to offer a simple alternative that uses just one form of the selected independent variable, the temperature range. It only corrects for extreme, mainly advective conditions, using mostly the points to the right of the dense cloud in Fig. 5A. 
In selecting alternative models, especially an intrinsically linear one, why not find a means of directly including the daily_average air temperature? Response surface methodology with $\Delta \mathrm{T}_{\mathrm{m}}(\mathrm{J})$ and $\Delta \mathrm{T}(\mathrm{J})$ and also with $\Delta \mathrm{T}(\mathrm{J}-1)$ added looks promising in each of two different approaches. Each was considered directly. Next $\tau_{\mathrm{m}}$ along with each temperature variable was subtracted from its annual cycle normal. Hook and McClendon (1992) did not consider any such options.

There are, however, some even more promising alternatives that should be tried. One possibility stems from observing that $\tau_{\mathrm{m}}, \Delta \mathrm{T}$ or $\Delta \mathrm{T}_{\mathrm{m}}$, and $\overline{\mathrm{T}}$ are all autocorrelated. In fact $\Delta \overline{\mathrm{T}}$ forms a nice stationary time series with a strong first lag term. Some form of time series analysis could prove useful, especially using $\Delta \mathrm{T}$ to find a means of modeling the advection. Another possibility is to try a more physically based approach which is possible with data available in the SAMSON database. Adaptations of simple broadband parameterizations such as Monteith's direct plus diffuse model (Monteith and Unsworth, 1990) are possible; one possibility is,

$$
\tau=\mathrm{a}_{0} \exp \left(-\sigma \mathrm{m}_{\mathrm{a}}\right)+\mathrm{a}_{1} / \sigma+\mathrm{a}_{2}
$$

In eq. (5) $a_{0}, a_{1}$, and $a_{2}$ are model parameters and $\sigma$ is the independent variable, a turbidity coefficient which can be constructed from aerosol optical depth and precipitable water parameters in the SAMSON database. SAMSON also has diffuse solar radiation, sky cover, and many other variables which could be used to develop and modify eq. (5). Preliminary assessment reveals $\sigma$ is linear with $T$, i.e, diffuse is linear with $\sigma$. Moreover findings make sense physically.

Finally there is a question of the appropriateness of using ordinary regression methodology with the usual assumptions. It has been pointed out that all of the variables are autocorrelated, non-normal, and the development and prediction results indicate heteroscedasticity. Another consideration is that the data are a serial sampling of the environment at one location used to represent a large area, i.e., a random field (Vanmarcke, 1983). Hence, essentially, they are happenstance data. Using OLS regression assumes the effects are fixed. A 30 year period of record may address any range considerations but not possible measurement error in the predictors. Ample consideration needs to be given to this issue. In eq. (3) the use of Draper's (1991) geometric mean estimator suggests a slope value almost double that of the OLS estimate and would have a measurement error of $\pm 1.5 \mathrm{C}^{\circ}$ (the measurement error estimate is based on back calculation from a method of moments slope estimator). Temperature data from a rain gage network associated with the previously mentioned base station located in the 5600 ha Walnut Creek Watershed just south of Ames suggest a measurement error of $\approx \pm 1 \mathrm{C}^{\circ}$. The resulting slope would be $\approx 20 \%$ larger. Hence the assessment of the effect of a measurement error is paramount. Furthermore, with Carroll et al. (1995) nonlinear measurement error methodology, eq. (5) could be modeled directly from non-SAMSON sites.

\section{Conclusion}

The Bristow-Campbell Model, especially as formulated in eq. (2b) is a poor choice given the researcher's stated purpose. This conclusion is based on established statistical methodology accepted in the researchers' field. In this comparison much simpler alternatives cast in the chosen predictor variable, temperature range, work better. Furthermore, there are many other things that should be considered to soundly develop a model. These considerations include finding a better means to account for advection, developing and evaluating other models, and 
justifying the assumptions of the methodology to be employed. I plan to work on these problems and then to notify the researchers of the unpublished work that I reviewed of any significant findings.

\section{Acknowledgments}

This work was supported by the USDA-ARS-MWA National Soil Tilth Laboratory (NSTL), Dr. J.L. Hatfield, Director. I thank the authors of the unpublished manuscript for interesting me in the problem. Prof. R.E. Carlson, ISU, Ames, IA, provided the Ames solar radiation data and comments on the manuscript. Dr. Bruce Mackey, USDA-ARS-PWA Biometrics and an anonymous reviewer also provided comments and advice.

\section{References}

Baker, D.G. and Klink, J.C. (1975), Solar radiation reception, probabilities, and areal distribution in the North-Central Region, NCR Pub. 225 - Univ. MN Agric. Exp. Stn. Tech. Bull., 300, St. Paul: Univ. MN.

Berg, R.L. (1992), First place. "Best presentation of data-Monochrome," Proc. 17th Annual SAS Users Group Intl. Conf. Honolulu, HI, SAS Inst., Inc., Cary, NC, 1521-1527.

Bland, W.L., and Clayton, M.K. (1994), "Spatial structure of solar radiation in Wisconsin," Agric. For. Meteorol., 69, 75-84.

Bristow, K.L., and Campbell, G.S. (1984), "On the relationship between incoming solar radiation and daily maximum and minimum temperature," Agric. For. Meteorol., 31, 159-166.

Carroll, R.J., Ruppert, D.R., and Stefanski, L.A. (1995), Measurement error in nonlinear regression models: Monographs on statistics and applied probability, New York: Chapman and Hall. Draper, N. (1991), "Straight line regression when both variables are subject to error." in Proc. 1991 Kan. St. Univ. Conf. Appl. Stat. Agric., eds. G.H. Milliken and J.R. Schwenke, Manhattan: KSU Dept. Stats.

Fox, D.G., workshop chair. (1981), "Judging air quality model performance: A summary of the AMS workshop on dispersion model performance", Bull. Am. Meteorol. Soc., 62, 599-609.

Hargreaves, G.L., Hargreaves, G.H., and Riley, J.P. (1985), "Irrigation water requirements for Segegal River Basin," J. Irrig. Drng. Engr., ASCE 111(3), 265-275

Hook, J.E. and McClendon, R.W. (1992), "Estimation of solar radiation data missing from longterm meteorological records," Agron. J., 84, 739-742.

Iqbal, M. (1983), An introduction to solar radiation, New York: Academic Press.

Lean, J., Beer, J., and Bradley, R. (1995), "Reconstruction of solar irradiance data since 1610: Implications for climate change", Geoph. Res. Let., 22(23), 3195-3198.

Meek, D.W., Hatfield, J.L., Howell, T.A., Idso, S.B., and Reginato, R.J. (1984), “A generalized relationship between photsynthetically active radiation and solar radiation", Agron. J., 76, 939-945.

Meek, D.W. (1997), "Estimation of maximum possible daily global solar radiation", Agric. For. Meteorol., 87, 223-241.

Monteith, J.L. and Unsworth, M.H. (1990), Principles of environmental physics, second ed., New York: Edward Arnold. 
National Renewable Energy Laboratory (NREL). (1992), NRSDB Vol. 1. User's Manual-

National solar radiation data base (1961-1990), Golden: USDOE-NREL.

National Renewable Energy Laboratory (NREL). (1993), Users manual for the SERI QC

Software: Assessing the quality of solar radiation data, Golden: USDOE-NREL.

National Renewable Energy Laboratory (NREL). (1995), NRSDB Vol. 2. Final technical report -

National solar radiation data base (1961-1990). Golden: USDOE-NREL.

Richardson, C.W. (1985), "Weather simulation for crop management modeling", Trans. Am. Soc. Agric. Engr., 28(5), 1602-1606.

Meyer, S.J. and Hubbard, K.G., (1992), "Nonfederal automated weather stations and networks in the United States and Canada: a preliminary review", Bull. Am. Meteorol. Soc., 73(4), 449-457.

Sauer, P. and Hatfield, J. (1994), Walnut Creek Watershed research protocol report. B94-1,

Ames: USDA-ARS-NSTL.

United States Department of Commerce. (1972), National Weather Service Observing Handbook No. 2, Silver Spring: USDC-NOAA-NWS.

Vanmarcke, E. (1983), Random fields, analysis and synthesis, Cambridge: MTT Press.

Table 1. Quantitative measures of daily global solar radiation model performance for Ames, IA.

\begin{tabular}{|c|c|c|c|c|c|c|c|c|c|}
\hline Model $^{\mathrm{a}}$ & $\mathrm{N}$ & $\bar{O}$ & $\overline{\mathrm{P}}$ & Ratio & $\mathrm{r}$ & MAE & RMSE & $\operatorname{Bias}(\mathrm{MBE})$ & $\mathrm{S}_{\mathrm{d}}^{2}$ \\
\hline Eq. $(2 b)$ & 10921 & $14.10(13.06)$ & $15.45(13.86)$ & 0.9122 & $0.7893(0.7921)$ & 3.89 & 5.21 & $-1.36 \pm 0.048$ & 25.28 \\
\hline Eq. $(2 c)$ & 10921 & $14.10(13.06)$ & $15.45(15.13)$ & 0.9122 & $0.7891(0.7821)$ & 3.90 & 5.25 & $-1.36 \pm 0.049$ & 25.72 \\
\hline Eq. (3) & 10921 & $14.10(13.06)$ & $15.14(14.80)$ & 0.9311 & $0.7981(0.8010)$ & 3.89 & 5.02 & $-1.04 \pm 0.047$ & 24.16 \\
\hline Eq. (4) & 10921 & $14.10(13.06)$ & $15.26(14.76)$ & 0.9240 & $0.8059(0.8035)$ & 3.76 & 4.97 & $-1.16 \pm 0.046$ & 23.32 \\
\hline
\end{tabular}

${ }^{\mathrm{a}}$ Terminology

Model: Equation numbers are the same as those provided in the methods section.

N: Number of observations.

O: $\quad$ Mean observed value of daily measurements $\left[\mathbf{R}_{\mathrm{s}}(\mathrm{d})\right]$ in $\mathrm{MJ} \mathrm{m}^{-2}$ (median value).

$\overline{\mathrm{P}}$ : $\quad$ Mean predicted value of daily measurements $\left[\hat{\mathbf{R}}_{\mathrm{s}}(\mathrm{d})\right]$ in $\mathrm{MJ} \mathrm{m}^{-2}$ (median value).

Ratio: (Mean observed)/(Mean predicted)

r: $\quad$ Pearson product-moment correlation coefficient (Spearman rank correlation coefficient).

MAE: Mean absolute error $\left(\mathrm{MJ} \mathrm{m}^{-2}\right)$.

RMSE: Root mean square error $\left(\mathrm{MJ} \mathrm{m}^{-2}\right)$.

Bias: Mean bias error $\left(\mathrm{MJ} \mathrm{m}^{-2}\right)$.

$\mathrm{S}_{\mathrm{d}}{ }^{2}$ : $\quad$ Bias variance. 
Figure 1. Extraterrestrial $\left(\mathbf{R}_{\text {Sext }}\right)$ and clear day $\left(\mathbf{R}_{\mathrm{Sc}_{\mathrm{c}}}\right)$ solar radiation curves developed for Ames, IA are drawn to the left axis scale. The corresponding daily average relative optical air mass curve $\left(m_{a}\right)$ is drawn to the right axis scale.

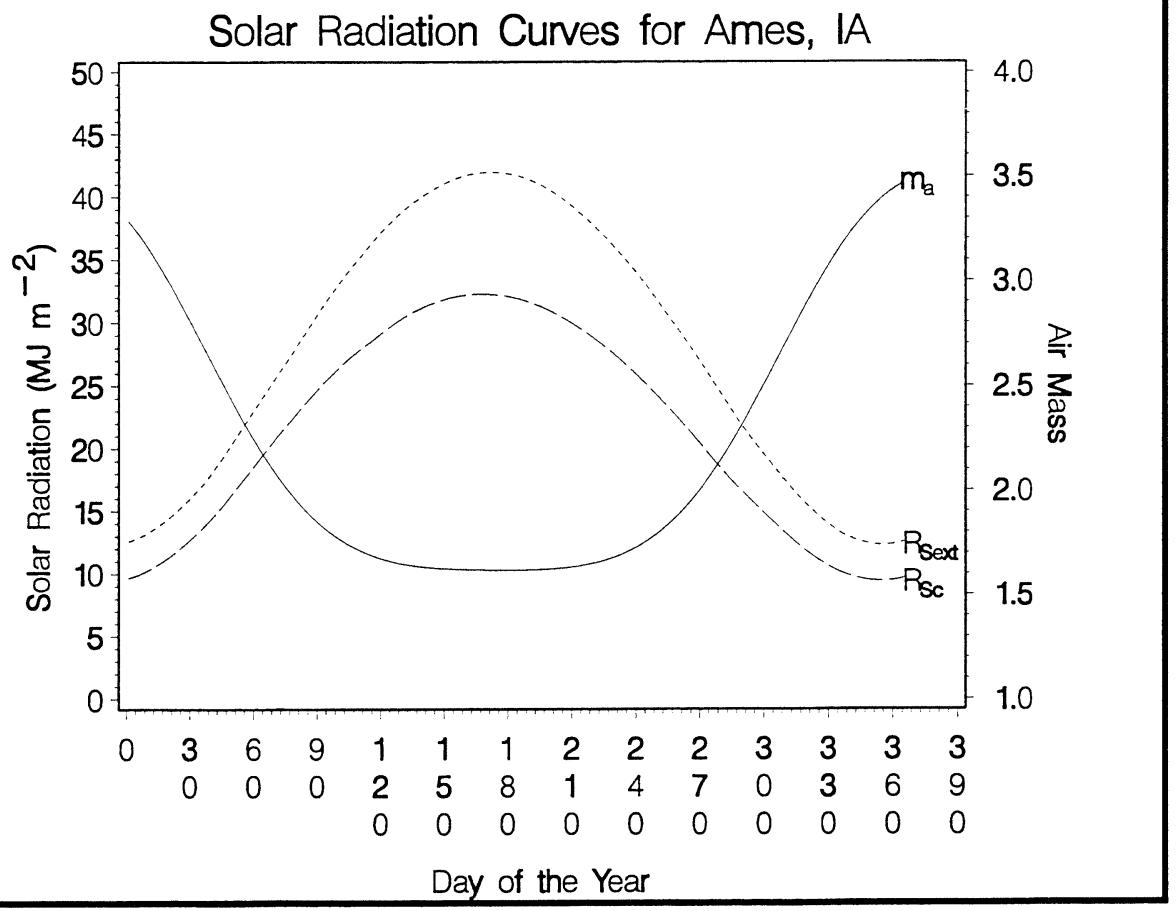


Figure 2. Bristow-Campbell Models for the Ames, IA data set: Berg-plots for eq. (2b) crossvalidation (A) and for eq. (2c) cross-validation (C). Corresponding annual cycle time plots for the observed - eq. (2b) and observed - eq. (2c) prediction differences (B and D).
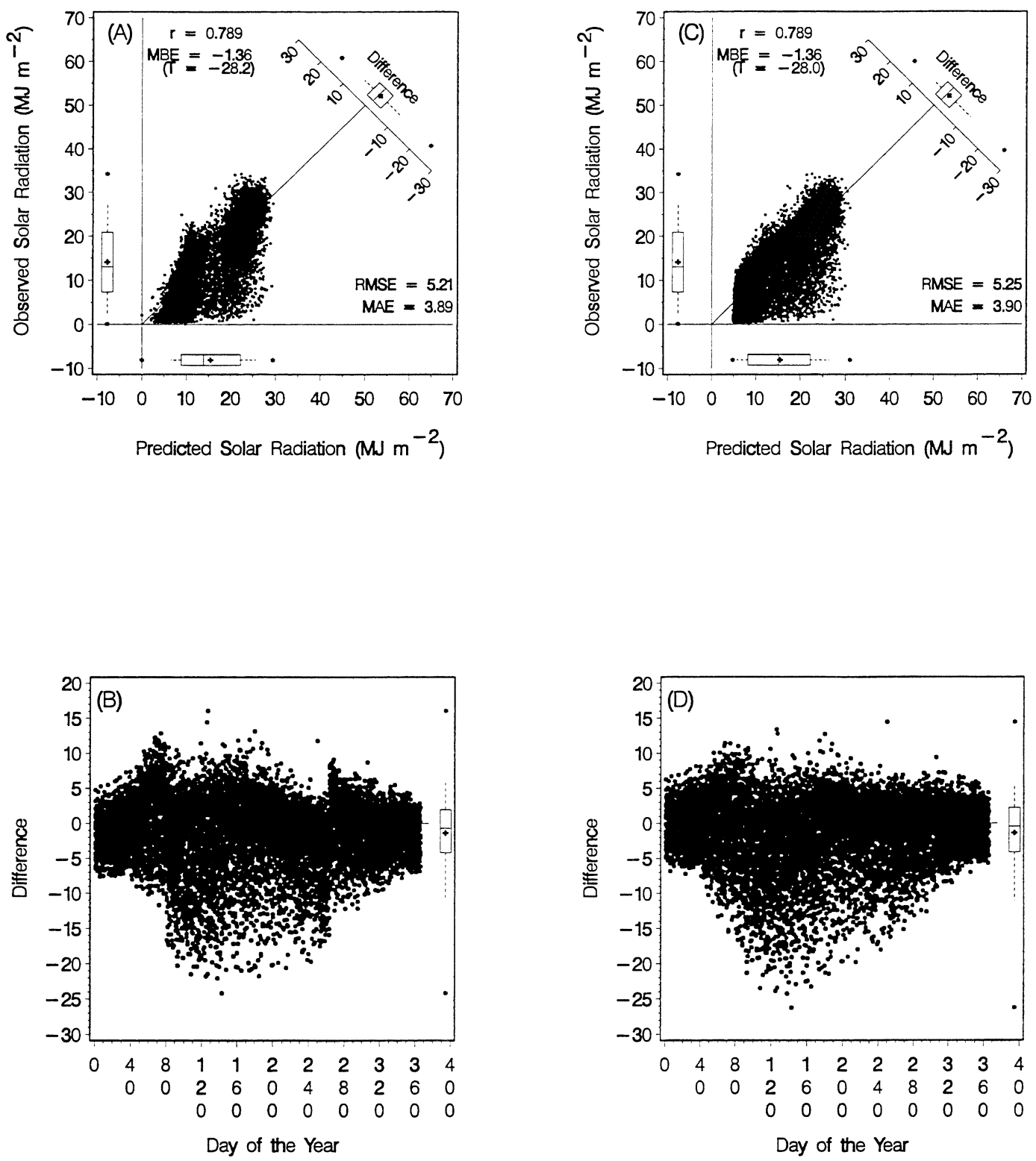
Figure 3. Alternative models for the Ames, IA data set: Berg-plots for eq. (3) cross-validation (A) and for eq. (4) cross-validation (C). Corresponding annual cycle time plots for the observed eq. (3) and observed - eq. (4) prediction differences (B and D).
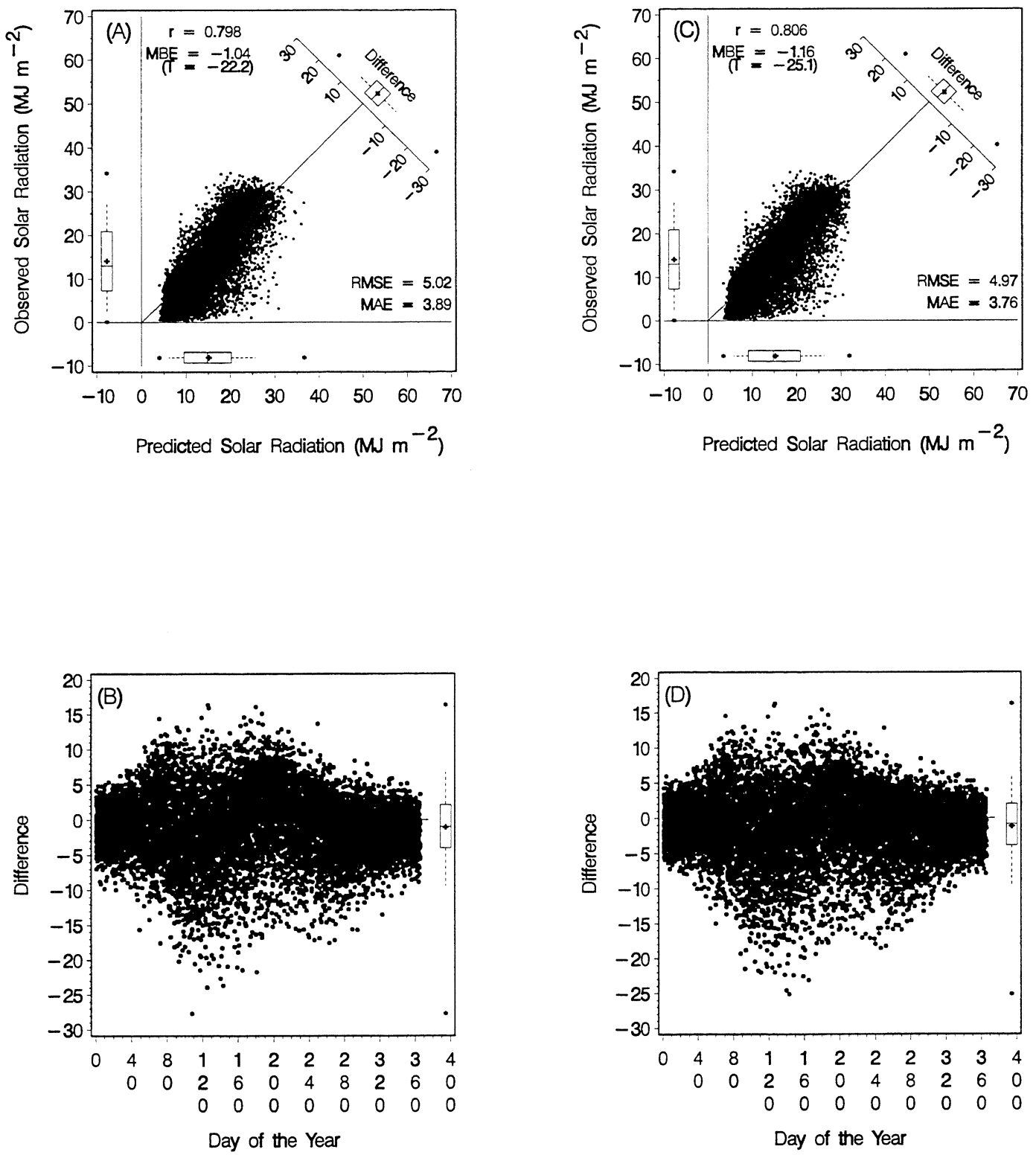
Figure 4. Scatterplots for $\tau$ vs. $\Delta \mathrm{T}, \Delta \mathrm{T}_{\mathrm{a}}$, and $\Delta \mathrm{T}_{\mathrm{b}}$ for all Ames data (frames $\mathrm{A}\{\mathrm{r}=0.505\}, \mathrm{B}\{\mathrm{r}=0.419\}$, and $\mathrm{C}\{\mathrm{r}=0.492\}$, $\mathrm{n}=10921$ ) and for median based daily normals (frames $\mathrm{D}\{\mathrm{r}=0.519\}, \mathrm{E}\{\mathrm{r}=0.432\}$, and $\mathrm{F}\{\mathrm{r}=0.487\}, \mathrm{n}=365$ ). In frames $A, B$, and $\mathrm{C}$ points associated with possible advective conditions are shown as $\star$ and are selected when $|\Delta \overline{\mathrm{T}}(\mathrm{J})|>4^{\circ} \mathrm{C}$ or when $\mid \Delta \overline{\mathrm{T}}(\mathrm{J}-$ 1) $>4^{\circ} \mathrm{C}$
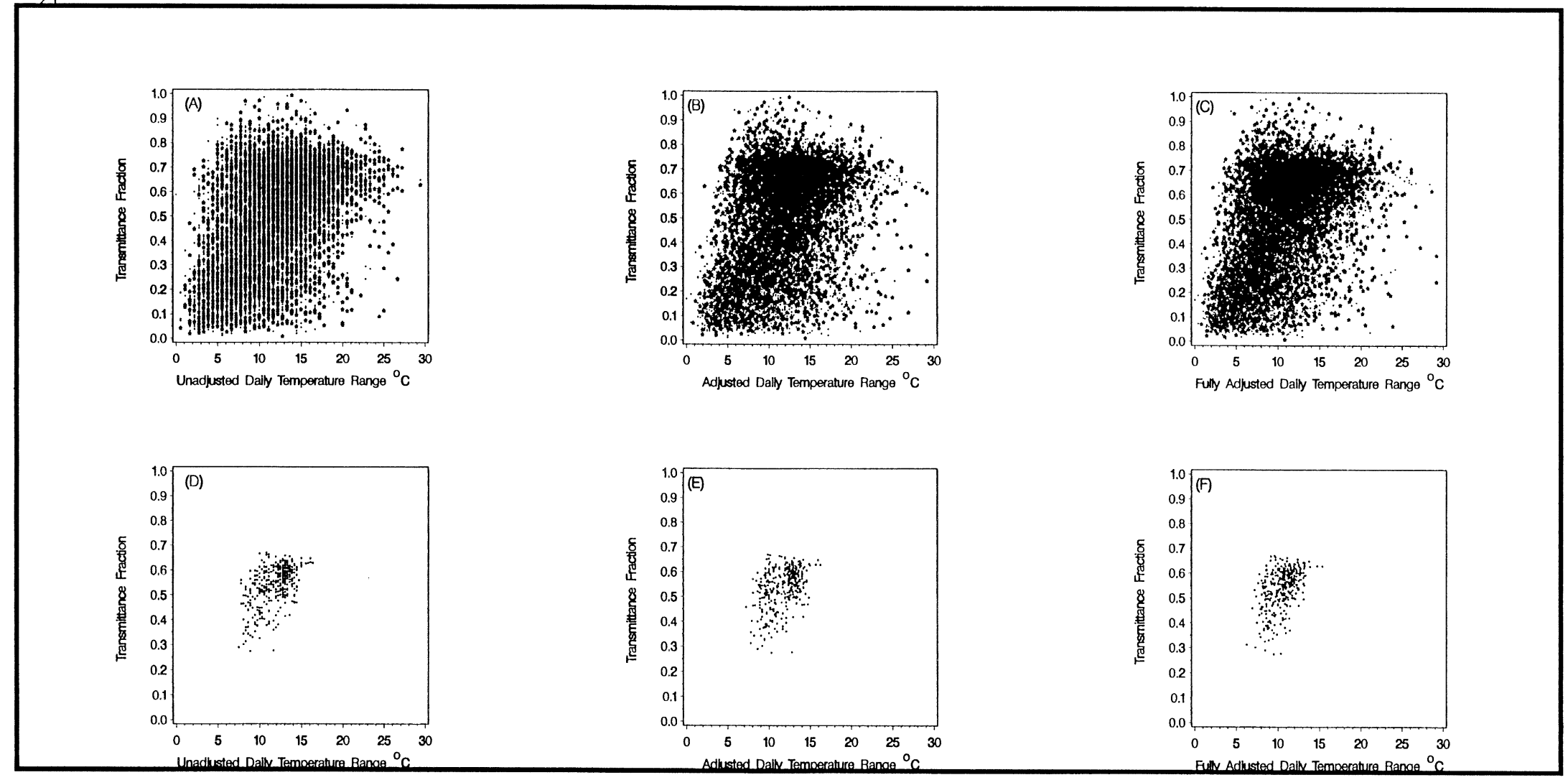

$\vec{\omega}$ 
Figure 5. Scatterplots for $\tau_{m}$ vs. $\Delta \mathrm{T}_{\mathrm{m}}$ for all Ames data $(\mathrm{A}\{\mathrm{r}=0.697\}, \mathrm{n}=10921)$ and for median based daily normals ( $\mathrm{B}\{\mathrm{r}=0.912\}, \mathrm{n}=365$ ). In frame $\mathrm{A}$, points associated with possible advective conditions are shown as $\star$ and are selected when $|\Delta \overline{\mathrm{T}}(\mathrm{J})|>4^{\circ} \mathrm{C}$ or when $|\Delta \overline{\mathrm{T}}(\mathrm{J}-1)|>4^{\circ} \mathrm{C}$.
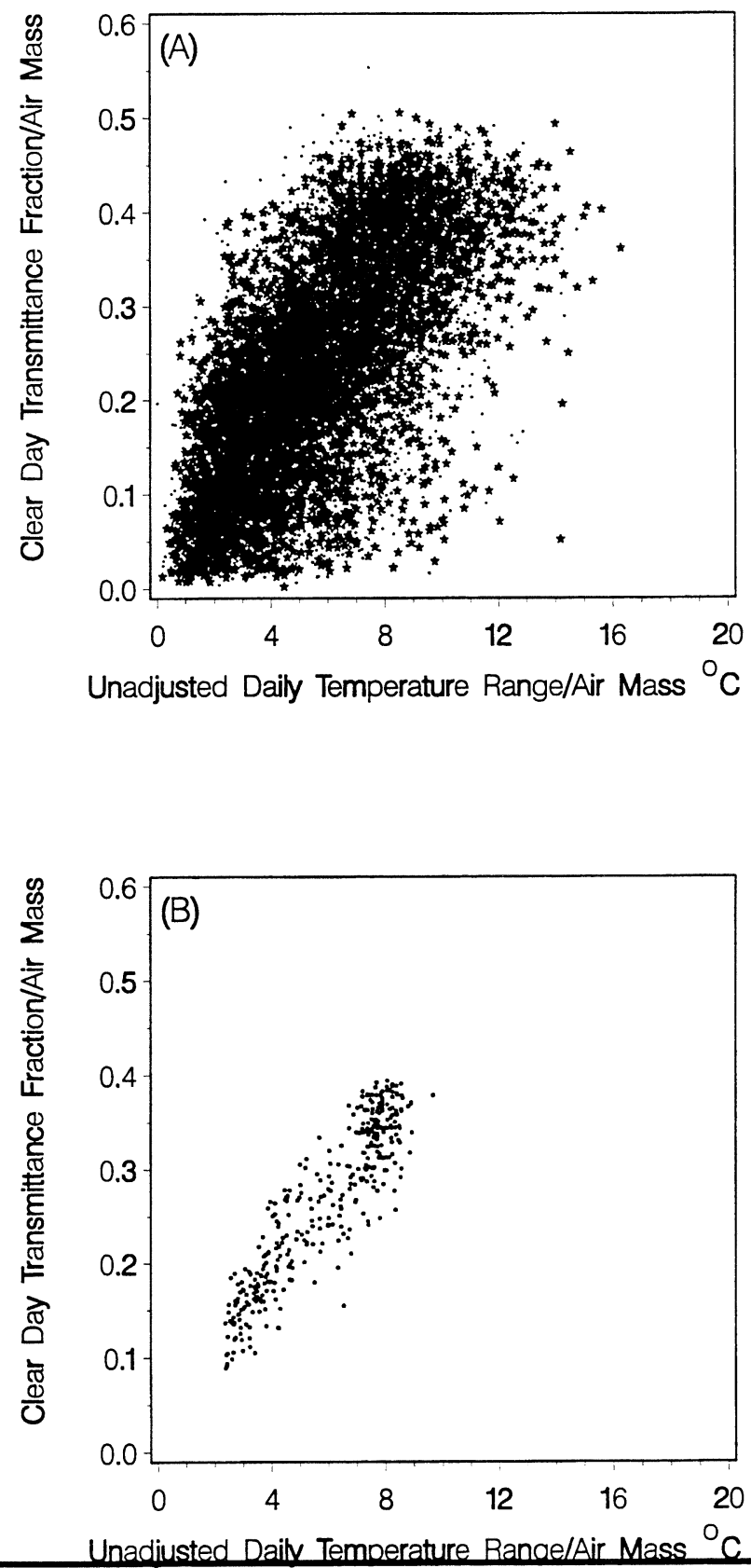